\title{
A prevalência da pneumonia nosocomial e sua relação com a doença periodontal: revisão de literatura
}

\section{Prevalence of nosocomial pneumonia and its relation to periodontal disease: literature review}

Samantha Simoni Santi*

Rubem Beraldo dos Santos ${ }^{* *}$

\section{Resumo}

Objetivo: o presente trabalho pretende realizar uma revisão de literatura buscando estimar a prevalência da pneumonia nosocomial e verificar se há associação com a doença periodontal. Revisão da literatura: a pneumonia nosocomial é uma infecção do parênquima pulmonar causada por diferentes tipos de agentes etiológicos, resultando no desequilíbrio entre os mecanismos imunitários, especialmente em indivíduos internados em unidade de terapia intensiva. Sua ocorrência é reconhecida como um importante problema de saúde pública no Brasil e no mundo, com um aumento significativo de sua prevalência. A colonização do biofilme dental e a doença periodontal podem ter um papel muito importante como reservatório de microrganismos causadores dessa infecção, uma vez que a pneumonia nosocomial resulta da aspiração da flora da orofaringe para o trato respiratório inferior. Considerações finais: a literatura estudada sugere, seguramente, a relação da doença periodontal no estabelecimento da pneumonia nosocomial. Considerando que no Brasil essa infecção ocorre em um décimo dos pacientes internados na unidade de terapia intensiva, torna-se ainda mais importante o conhecimento da prevalência e de seus fatores associados para se pensar em estratégias eficazes de controle da doença.

Palavras-chave: Biofilme dentário. Pneumonia. Prevalência. Unidade de terapia intensiva.

\section{Introdução}

Há muito tempo, têm-se indícios da relação entre doenças bucais e sistêmicas, sendo os primeiros relatos dessa associação datados de 2100 a.C. Desde então, inúmeras pesquisas foram desenvolvidas apresentando resultados que evidenciam cada vez mais essa possível interface ${ }^{1}$. Os efeitos das doenças bucais para o organismo não podem ser considerados limitados e triviais, pois interferem na qualidade de vida, geram dor, desconforto, reduzem a função mastigatória e a qualidade de fonação. Limitações sociais e de convívio pessoal também ocorrem, diminuindo a produtividade individual ${ }^{2}$.

A pneumonia nosocomial (PNC) ou hospitalar afeta o parênquima pulmonar. Segundo a Agência Nacional de Vigilância Sanitária (Anvisa) ${ }^{3}$ (2005), o número de óbitos por infecção hospitalar pode chegar a 100 mil a cada ano. O risco de desenvolver a PNC aumenta com o uso da ventilação mecânica (VM) e a doença prolonga, em média, por cinco a nove dias o tempo de internação, aumentando custos hospitalares ${ }^{4}$. Na etiopatogenia da PNC, tem-se que a contaminação das vias aéreas por patógenos bucais é, provavelmente, devida à aspiração e/ou inalação de saliva contaminada por bactérias bucais, lipopolissacarídeos e enzimas bacterianas ${ }^{5}$.

Acadêmica de Odontologia na Universidade Luterana do Brasil, Cachoeira do Sul, RS, Brasil.

Doutor em Estomatologia Clínica pela Pontifícia Universidade Católica do Rio Grande do Sul. Especialista em Endodontia pela Universidade Federal de Pelotas. Professor e coordenador do curso de Odontologia da Universidade Luterana do Brasil, Cachoeira do Sul, RS, Brasil. 
Por sua vez, a doença periodontal (DP) é a segunda patologia mais prevalente nos tecidos bucais e, diante da resposta positiva das políticas públicas no combate à cárie, acredita-se que, em um futuro próximo, a DP torne-se o agravo mais comum em saúde bucal. Essa doença, além de trazer prejuízos ao sistema estomatognático, pode desencadear importantes repercussões a distância no organismo ${ }^{6}$.

Há tempos que a periodontia reconhece a influência de fatores sistêmicos sobre o estabelecimento e a progressão da doença periodontal. $\mathrm{O}$ caminho inverso, ou seja, a influência da doença periodontal sobre determinadas condições sistêmicas, tem sido muito estudado nos últimos anos, delineando um novo campo de investigação, conhecido como medicina periodontal. Dentre as principais condições estudadas está o nascimento de bebês prematuros e/ou com baixo peso ${ }^{7}$, doenças cardiovasculares, diabetes e as afecções do trato respiratório ${ }^{3}$. Nesse grupo de doenças, insere-se a PNC, considerada um problema de saúde pública, devido à grande taxa de mortalidade e por manter o paciente mais tempo em ambiente hospitalar ${ }^{8}$. A microaspiração do conteúdo da orofaringe é causa de alterações respiratórias, tais como pneumonias e abscessos pulmonares. $\mathrm{O}$ acúmulo de patógenos bucais pode facilitar a infecção das vias aéreas por novos microrganismos. Nesse contexto, o modelo de plausibilidade biológica que inter-relaciona a PNC e a DP justifica-se pelo fato de a proliferação bacteriana na DP favorecer a colonização orofaríngea, perpetuando o quadro infeccioso bucal por meio de mediadores inflamatórios e imunológicos. Dessa forma, ocorre maior atividade proteolítica e a consequente alteração da mucosa, tornando a cavidade bucal susceptível à colonização de patógenos da $\mathrm{PNC}^{9-11}$.

$\mathrm{Na}$ literatura, existem trabalhos que avaliaram a associação DP e PNC, mas os achados parecem ainda sem consenso, pois alguns autores defendem tal associaçã $0^{4,9-13}$ enquanto outros não a consideram como fato científico consolidado ${ }^{8,14}$, por isso a necessidade de mais estudos sobre esse importante tema. Portanto, o objetivo do presente trabalho é fazer uma revisão de literatura buscando estimar a prevalência da PNC e sua possível associação com a DP.

\section{Métodos}

$\mathrm{Na}$ pesquisa bibliográfica, consultaram-se as bases de dados PubMed, Bireme PAHO-WHO, Lilacs, BBO, SciELO e Portal Capes, com as palavras de busca prevalência, biofilme dentário, pneumonia, nosocomial e unidade de terapia intensiva, no período de 1970 a 2015.

\section{Revisão de literatura}

\section{Pneumonia nosocomial}

\section{Conceito da pneumonia nosocomial}

Pneumonia é uma infecção aguda pulmonar que pode produzir sinais e sintomas respiratórios tais como tosse, respiração curta e rápida, produção de secreção e dores no peito, além de febre, fadiga, dores musculares e falta de apetite ${ }^{15}$.

Em um quadro de PNC, a via principal para a entrada de microrganismos no trato respiratório inferior consiste na aspiração de secreção da orofaringe. A pneumonia relacionada à assistência tem sido definida da seguinte forma: pneumonia adquirida no hospital (PAH) é aquela que ocorre após 48 horas da admissão hospitalar, geralmente tratada na unidade de internação, não se relacionando à ventilação mecânica. Devido a implicações etiológicas, terapêuticas e prognósticas, a PAH é classificada quanto ao tempo decorrido desde a admissão até o seu aparecimento: a PAH precoce é aquela que ocorre até o quarto dia e a tardia, após cinco dias de internaçãa $0^{16}$.

Quando o paciente é encaminhado para internação na unidade de terapia intensiva (UTI), com indicação de VM, poderão surgir indícios de infecção entre 48 e 72 horas após a intubação e o início da VM, sendo conceituada como pneumonia associada à ventilação mecânica $(\mathrm{PAVM})^{17}$.

\section{Etiopatogenia e prevenção da pneumonia nosocomial}

Em pacientes sob terapia intensiva, a higiene bucal costuma ser inadequada, tornando o biofilme um reservatório propício para microrganismos que agravam o processo infeccioso nos tecidos periodontais e, ainda, com o potencial para causar infecções a distância. O estabelecimento da PNC depende da colonização na orofaringe por patógenos respiratórios, da aspiração desses para as vias aéreas inferiores e também da capacidade desses microrganismos escaparem das defesas naturais. Ainda que a aspiração de pequenas quantidades de secreções da cavidade bucal seja comum em indivíduos saudáveis, especialmente durante o sono, em pacientes em estado de alteração do nível de consciência, as quantidades de secreções aspiradas tendem a aumentar ${ }^{5}$.

Acredita-se que o aumento da colonização microbiana, dentre inúmeros fatores, deve-se também ao fato de algumas espécies, como Candida albicans, se coagregarem e coaderirem a certas espécies microbianas, tais como estreptococos e patógenos do biofilme dental. Além disso, algumas proteínas salivares podem intensificar essas interações na presença de DP e cáries. Ademais, a presença da microbiota associada a alguns fatores predisponentes é necessária para o estabelecimento de infecções, tais 
como: queda de imunidade do hospedeiro, desordens endócrinas, lesões em mucosa, higiene bucal deficiente e tratamento prolongado com antibióticos e corticosteroides ${ }^{18}$. Estudos recentes apontam para um aumento da prevalência da PNC causada por bactérias gram-negativas multirresistentes, tais como Pseudomonas aeruginosa com resistência documentada a ß-lactâmicos, carbapenemos, aminoglicosídeos e fluoroquinolonas. Por tal motivo, a PNC produzida pela $P$. aeruginosa está associada com alta morbidade, prolongada internação, aumento de custos e maior risco de mortalidade ${ }^{19}$.

A literatura recomenda os seguintes critérios para o diagnóstico de PNC: evidências de infecções agudas caracterizadas pela presença de febre, leucocitose ou leucopenia; evidências de inflamação do trato respiratório inferior, tais como tosse, expectoração purulenta, aumento da secreção brônquica; infiltrado pulmonar novo ou progressivo identificado na radiografia de tórax; crescimento bacteriano em culturas do escarro, do aspirado traqueal, do lavado broncoalveolar e do líquido pleural ou do sangue ${ }^{2}$.

A prevenção dessa contaminação é o principal desafio para o controle de infecção hospitalar. A mais importante via de aquisição da PAVM é pela colonização orofaríngea, pela microbiota endógena ou por patógenos exógenos adquiridos no ambiente da UTI, especialmente por meio das mãos dos profissionais de saúde, de equipamentos respiratórios contaminados ou da contaminação da água do hospital $^{20}$.

Algumas medidas que podem ajudar no controle da PNC são a adoção de precauções padrão de contato, protocolos de prescrição de antimicrobianos de acordo com a microbiota, monitoramento constante pela comissão de infecção hospitalar, redução do tempo de intubação, manutenção da cabeceira elevada de 30 até 45 graus nos pacientes intubados, manutenção da pressão do balonete da cânula entre $20 \mathrm{mmHg}$ a $30 \mathrm{mmHg}$ para diminuir o conteúdo aspirado da orofaringe, realização da aspiração de secreções conforme a necessidade e não em horários programados, limpeza frequente da tubulação do ventilador mecânico, antissepsia bucal com clorexidina a $0,12 \%$, evitar sedação profunda e constante e, se possível, realizar despertares diários, realização de exercícios respiratórios diários em pacientes em pós-operatório, dar preferência à nutrição enteral para evitar atrofia do trato gastrointestinal, o que aumenta a translocação bacteriana ${ }^{16}$.

\section{Prevalência da pneumonia nosocomial}

Segundo Toews ${ }^{21}$ (1986), as estatísticas internacionais registravam mais de 300.000 infecções respiratórias nosocomiais por ano, causando em torno de 20.000 óbitos. A prevalência relatada pela American Thoracic Society ${ }^{22}$ (2005) era de 20,5 a 34,4 casos de pneumonia por 1.000 dias de VM e de 3,2 casos por 1.000 dias em pacientes não ventilados.
Mais de 5,6 milhões de casos de PNC acontecem anualmente nos Estados Unidos da América e a taxa geral de mortalidade é de $5 \%$.

Segundo informações da Anvisa ${ }^{3}$, no ano de 2005, não havia dados estatísticos oficiais disponíveis sobre a PNC no Brasil. Essa agência refere também que a PAVM é a principal infecção em UTI, sendo sua incidência em pacientes adultos entre 7 e 46 casos em cada 1.000 internações. A prevalência estimada de PNC, em UTI, varia entre $10 \%$ e $65 \%$ e o número de óbitos por infecção hospitalar é de 100 mil a cada ano. Em um estudo brasileiro de prevalência de um dia em 16 UTIs, no estado do Rio Grande do Sul, dos 122 pacientes avaliados, 58,2\% estavam com $\mathrm{PNC}^{23}$. Em outro estudo prospectivo, com duração de oito anos, Terpenning et al. ${ }^{24}$ (2001) avaliaram a importância de fatores médicos e odontológicos na pneumonia por aspiração em 358 pacientes, com idade a partir de 55 anos, procedentes de asilos, clínicas e hospitais. Realizaram-se, anualmente, exames médicos e odontológicos. As variáveis observadas foram o desenvolvimento de pneumonia, coleta de saliva para cultura, coleta de mucosa da orofaringe, biofilme supra e subgengival para detecção de espécies aeróbias e anaeróbias. Nesse estudo, $50(13,96 \%)$ pacientes desenvolveram PNC, 28 dos quais eram dentados, e a presença de Porphyromonas gingivalis no biofilme dental e de Streptoccocus sobrinus e Staphyloccocus aureus na saliva foi significativamente mais alta nos indivíduos com pneumonia por aspiração. Os pacientes dentados que tiveram PNC tenderam a ter maior número de dentes destruídos e, notavelmente, houve grande proporção de indivíduos com biofilme dental visível.

\section{Doença periodontal}

As doenças periodontais acometem os tecidos gengivais, quando são denominadas gengivite, e/ ou os tecidos de suporte dos dentes, então chamadas periodontite. Enquanto os microrganismos são essenciais para o desencadeamento da DP, a evolução e a extensão do dano estão relacionadas com a suscetibilidade do hospedeiro, ou seja, a extensão e a gravidade apresentam razões multifatoriais, em que condições de risco, tais como alterações sistêmicas e aspectos comportamentais, podem estar implicadas na etiopatogenia da doença ${ }^{25}$.

Cabe registrar que a gengivite é causada pelo biofilme bacteriano supragengival. Por sua vez, a periodontite corresponde à destruição do periodonto de sustentação e ocorre quando as alterações patológicas verificadas na gengivite progridem, até haver destruição do ligamento periodontal e migração apical do epitélio juncional. Nesse quadro, a placa bacteriana acumula-se ao nível subgengival, causando perda de inserção ${ }^{26}$.

$\mathrm{Na}$ análise da etiologia da $\mathrm{DP}$, ao contrário de outras patologias infecciosas clássicas, como tuberculose ou sífilis, que são causadas por um patógeno 
específico, deve-se considerar que a DP seja uma infecção que tem várias espécies microbianas que contribuem para seu desenvolvimento ${ }^{27}$. Ou seja, a microbiota implicada na gengivite é predominantemente composta por bactérias gram-positivas, aeróbias e sacarolíticas. Já na periodontite, predominam as gram-negativas, anaeróbias ou microaerófilas e proteolíticas, que colonizam a área subgengival, tais como: Bacteroides forsythus, Porphyromonas gingivalis, Aggregatibacter actinomycetemcomitans e Treponema denticola ${ }^{28}$.

\section{Influências da doença periodontal na pneumonia nosocomial}

A condição bucal parece estar relacionada ao estado de saúde geral do paciente, sendo assim, é plausível que se investigue a associação entre DP e patologias sistêmicas, neste caso, infecções respiratórias ${ }^{29}$. Considerando-se essa observação, a medicina periodontal surgiu alicerçada em estudos que demonstraram a relação direta entre a DP e uma série de morbidades, tais como aterosclerose, infarto agudo do miocárdio, prematuridade e baixo peso ao nascer, problemas respiratórios, gastrite e endocardite. Dentro desse grupo de doenças, pode ser inserido também o estudo da relação entre a PNC e a microbiota bucal ${ }^{12,30,31}$. Lindhe e Rylander ${ }^{32}$ (1975) já observavam que, após 24 horas sem limpeza da cavidade bucal, é possível detectar clinicamente uma camada de placa dental. Portanto, as manobras de higiene estão intimamente ligadas ao número e às espécies de microrganismos encontrados na boca.

$\mathrm{O}$ início da pneumonia bacteriana pode ser dependente da microbiota presente na cavidade bucal e na orofaringe, esses microrganismos configuram-se em potenciais patógenos respiratórios, especialmente, quando aspirados para as vias aéreas inferiores e se houver a falência dos mecanismos de defesa do hospedeiro ${ }^{13}$. Assim, sugere-se que existam mecanismos de associação do biofilme bucal com as infecções respiratórias por aspiraçã $0^{4,12}$.

$\mathrm{O}$ primeiro mecanismo sugerido seria quando o biofilme bucal originado da higiene deficiente, com altas concentrações de patógenos, tais como Porphyromonas gingivalis e Aggregatibacter actinomycetemcomitans, leva a uma alta concentração na saliva e pode ser aspirado para o pulmão, alterando as defesas imunes ${ }^{12}$

O segundo mecanismo dar-se-ia por condições específicas, em que o biofilme bucal poderia abrigar colônias de patógenos pulmonares. Assim, as bactérias presentes no biofilme facilitariam a colonização das vias aéreas superiores por patógenos pulmonares ${ }^{4}$.

Já o terceiro mecanismo é caracterizado pela aspiração do conteúdo da orofaringe, contendo partículas de alimentos e saliva carregadas de bactérias, a aglutinação dos patógenos periodontais nas células epiteliais pulmonares, levando ao aumento da aderência e da colonização por patógenos respirató- rios. Essa colonização induz a produção e secreção de mediadores inflamatórios e enzimas destrutivas, como a elastase, que degrada o tecido conjuntivo pulmonar $^{12}$

Com o objetivo de determinar o perfil periodontal de pacientes adultos traqueostomizados com PNC, Pinheiro et al. ${ }^{14}$ (2007) realizaram diagnóstico clínico e radiográfico de PNC e exame periodontal. Foram analisados quatro grupos: Grupo $1-1$ paciente sem PNC e sem DP; Grupo $2-7$ pacientes com PNC e sem DP; Grupo $3-3$ pacientes sem PNC e com DP; Grupo 4-22 pacientes com PNC e com DP. O índice de sangramento gengival foi maior nos pacientes com PNC $(41,03 \%)$ em relação aos pacientes sem essa patologia $(25,19 \%)$. Dos 33 pacientes examinados, 25 apresentaram periodontite, dos quais, 22 (88\%) tinham PNC. Os dados obtidos foram analisados por estatística descritiva, teste Exato de Fisher, U Mann Whitney e t-Student, não se comprovando associação estatisticamente significante entre as duas patologias $(p>0,05)$. Os autores concluíram que, apesar da higiene bucal deficiente e da maior prevalência de periodontite em pacientes com PNC, a associação entre elas não foi positiva.

Pineda et al. $^{8}$ (2006) realizaram pesquisa de metanálise de estudos randomizados controlados que avaliaram o efeito da antissepsia bucal com clorexidina a $0,12 \%$, duas vezes ao dia, na incidência da PNC. Os resultados demonstraram que o uso de descontaminação oral com clorexidina $0,12 \%$ não afetou a incidência da doença, indicando, assim, que a condição de saúde bucal não tem relação com a pneumonia nosocomial.

De outro modo, Shi et al. ${ }^{33}$ (2013) também realizaram metanálise investigando criticamente dezessete ensaios clínicos controlados e randomizados, publicados entre 2000 e 2012. Esses autores observaram que o uso de clorexidina comparado ao uso de placebos, associado ou não ao controle mecânico de placa, foi efetivo na redução da pneumonia por ventilação mecânica (OR 0,60-95\%CI 0,47 - 0,77, P $<0,001, \mathrm{I} 2=21 \%)$.

Em 2015, Chen et al. ${ }^{34}$ (2015) chegaram a uma conclusão semelhante analisando 6 artigos referentes a 132 pacientes submetidos à desinfecção bucal com clorexidina em comparação a 188 controles, que não se beneficiaram com o uso do antisséptico.

Os pacientes intubados apresentam maior risco de infecção hospitalar pelo fato de o tubo orotraqueal interferir nos reflexos do corpo para dissipar o que é aspirado. A intubação interfere também no reflexo da tosse e na sua depuração mucociliar, que impede a entrada de microrganismos no trato respiratório, estimula o excesso de secreções e, além disso, o ar inspirado não é aquecido e umedecido pelas vias respiratórias superiores, mas é artificialmente aquecido e umidificado pelo aparelho de ventilação, como resultado, a depuração mucociliar é impedida ${ }^{35}$. 
A presença de Porphyromona gingivalis no biofilme supragengival, associada à colonização bucal por patógenos periodontais com o risco de pneumonia por aspiração dessa bactéria e de alguns outros microrganismos periodontais, que são proteolíticos capazes de degradar a fibronectina, levou à hipótese de que a atividade proteolítica das bactérias periodonto-patogênicas pode alterar a superfície das células epiteliais da mucosa, comprometendo a barreira protetora e permitindo, assim, a colonização secundária da mucosa bucal com potenciais patógenos respiratórios, o que mais uma vez suporta a ideia da importância da DP como fator de risco para a pneumonia por aspiração ${ }^{6}$.

No estudo realizado por Cruz e Ziviani ${ }^{36}$ (2006), foram detectados patógenos respiratórios colonizando o biofilme dental em pacientes internados na UTI. Amostras de biofilme dental e da secreção traqueal dos pacientes que desenvolveram infecções respiratórias foram coletadas e analisadas por meio de cultura microbiológica, e os microrganismos identificados foram: Staphylococcus sp., Klebsiella pneumoniae, Pseudomonas aeruginosa e Enterobacter aerogenes. Além da análise microbiológica, foi possível observar relação entre a melhor condição da saúde bucal e a redução na prevalência de infecções respiratórias nos pacientes submetidos ao protocolo de limpeza bucal. Esses mesmos autores observaram que as espécies de Staphylococcus e, em especial, bastonetes gram-negativos anaeróbios contribuem significativamente para a pneumonia em pacientes na UTI. Os estreptococos anaeróbios e microaerófilos, bacterioides fusobacterium, bem como H. influenzae, Klebsiella pneumoniae e Staphylococus auereus estão fortemente envolvidos na etiopatogenia da pneumonia.

\section{Discussão}

Desde as décadas de 1970 e 1980, alguns autores identificaram que bactérias presentes no biofilme dental poderiam colonizar a orofaringe. Os resultados desses estudos sugerem a possibilidade de que as bactérias responsáveis pela $\mathrm{PNC}$ nos pacientes internados na UTI podem ser provenientes da $\mathrm{DP}^{28}$. Esses resultados corroboram os achados da pesquisa realizada por Scannapieco e $\mathrm{Ho}^{12}(2001)$ sobre a colonização bacteriana do biofilme dental em pacientes internados na UTI, em que, devido ao caráter infeccioso da patologia e aos mecanismos etiopatogênicos complexos semelhantes entre periodontite e PNC, foram propostas algumas hipóteses de plausibilidade biológica, a saber: aspiração direta de patógenos, ação facilitadora de enzimas e citocinas associadas à periodontite na colonização bucal de microrganismos do trato respiratório e alteração no epitélio de revestimento do trato respiratório por esses mesmos mediadores biológicos, facilitando a infecção dos patógenos respiratórios.
Em antagônica linha de raciocínio aos estudos anteriores, Pinheiro et al. ${ }^{14}$ (2007) demonstraram que uma condição de higiene bucal mais precária e maior prevalência de periodontite em pacientes com PNC não se configuraram uma correlação positiva entre essas patologias. Alguns dos motivos que podem ter contribuído para não se comprovar essa associação foram a amostra reduzida e não ter sido identificado pareamento entre os grupos estudados, ficando três grupos com, no máximo, sete componentes.

Pineda et al. ${ }^{8}$ (2006) demonstraram que o uso de descontaminação oral com clorexidina $0,12 \%$ não resultou em redução significativa na incidência de PNC em pacientes que receberam a VM, nem alterou a taxa de mortalidade. Outros estudos sugerem que a colonização de biofilme com bactérias patogênicas pode ser um precursor para a PNC. A descontaminação com base de clorexidina $0,12 \%$ da flora microbiana oral como estratégia isolada pode não ser suficiente para reduzir a carga de bactérias responsáveis por PNC. Além disso, não se pôde observar na metodologia desses autores se outros fatores críticos para o aparecimento da PNC, tais como a manutenção dos aparelhos respiratórios, a inclinação da cabeceira da cama, a realização da aspiração de secreções e a limpeza frequente da tubulação do ventilador mecânico tenham sido devidamente controlados ${ }^{16}$, embora se assuma que tais cuidados sejam protocolares em UTIs. Em oposição a esses achados, outros dezessete estudos, publicados entre 2000 e 2012 , sinalizam que o uso sistemático de clorexidina seja método bastante útil na prevenção da $\mathrm{PNC}^{33}$, além de um estudo publicado em $2015^{34}$, que também traz fortes evidências nesse sentido.

Quanto à prevalência das $\mathrm{PNCs}$, pode-se observar que os estudos estatísticos internacionais parecem ser mais consistentes. Nesse contexto, em diferentes estudos, a prevalência registra valores de 20,5 a 34,4 casos de pneumonia por 1.000 dias de VM e de 3,2 casos por 1.000 dias em pacientes não ventilados ${ }^{24}$.

No Brasil, apesar dos esforços da Anvisa ${ }^{3}$ (2005) em padronizar critérios nacionais para o registro das infecções respiratórias, parece que ainda não há muitos indicadores oficiais disponíveis, por isso a escassez de dados estatísticos. Outra razão desfavorável para a constante avaliação da PNC é a rotatividade dos leitos, já que a maioria dos municípios brasileiros tem dificuldades de comportar todos os pacientes que necessitam de UTI.

Sendo assim, a taxa de prevalência da PNC reflete-se, em grande parte, nos fatores relacionados ao paciente, à instituição e às características regionais, fazendo com que nos Estados Unidos da América o conhecimento epidemiológico dessa doença esteja mais avançado. Mesmo assumindo-se tal dificuldade, a Anvisa registra dados variáveis de prevalência entre $10 \%$ e $65 \%$, em função da população estudada ${ }^{3}$. Não muito diferente desses achados, 
Lisboa et al. ${ }^{23}$ (2007) observaram a prevalência de $58 \%$ da PNC.

Ao finalizar a discussão dos dados da literatura sobre a influência da DP na PNC, espera-se que as informações elencadas neste estudo contribuam para aumentar o corpo de evidências sobre a inter-relação entre as duas doenças, consideradas graves problemas de saúde pública. Para expandir os limites do presente estudo, sugere-se que pesquisas in vitro e in vivo sejam realizadas para investigar com mais profundidade tipos de microrganismos da DP que estão presentes na PNC e também para melhorar o entendimento do mecanismo e do potencial da ação desses microrganismos, na busca de minimizar os efeitos e a frequência de infecções respiratórias em pacientes hospitalizados.

\section{Considerações finais}

Os dados revisados e discutidos no presente estudo sugerem que no Brasil a PNC pode ocorrer no mínimo em um décimo dos pacientes internados na UTI, tornando ainda mais importante o conhecimento da prevalência da doença e seus fatores associados para se pensar em estratégias eficazes de controle. A relação da DP no estabelecimento da PNC é sugerida pela maioria dos autores analisados, mesmo que, em oposição a essa afirmação, alguns estudos não tenham efetivamente comprovado essa relação causal. Talvez, deva-se considerar que aqueles trabalhos que não demonstraram essa inter-relação apresentaram algumas limitações metodológicas, que, ao serem sanadas no futuro, poderão dar respostas mais conclusivas sobre tão importante tema. Em adição, embora exista alguma discordância na literatura, estudos metodologicamente bem delineados demostram que o efetivo uso de clorexidina a $0,12 \%$, associado a rotinas de higiene bucal e cuidados protocolares padrão em UTIs, é uma estratégia muito válida para prevenção e controle da PNC.

\section{Abstract}

Objective: The present study aimed to perform a literature review seeking to estimate the prevalence of nosocomial pneumonia and its potential relation to periodontal disease. Literature review: Nosocomial pneumonia is an infection of the pulmonary parenchyma caused by different etiological agents, resulting in the imbalance of immunity mechanisms, especially in subjects admitted to Intensive Care Units. Its occurrence has been recognized as an important public health problem in Brazil and around the world with significant prevalence increase. Dental biofilm colonization and periodontal disease may play an important role as reservoirs of microorganisms responsible for this infection, considering that nosocomial pneumonia results from the aspiration of the oropharyngeal flora to the lower respiratory tract. Final considerations: The studied literature strongly suggests the relation of periodontal di- sease to the establishment of nosocomial pneumonia. Considering that in Brazil this infection may occur from one tenth of the patients in Intensive Care Units, it becomes even more important to know its prevalence and associated factors, so to plan effective control strategies.

Keywords: Dental Biofilm. Pneumonia. Prevalence. Intensive Care Unit.

\section{Referências}

1. O'Reilly PG, Glaffey NM. History of oral sepsis as a cause of disease. J Clin Periodontol 2000; 23:13-8.

2. Rodrigues R, Serpa AP. Perfil bioemocional do paciente e o controle de placa bacteriana. In: Oppermann RV, Rosing CK. Periodontia, ciência e clínica. São Paulo: Artes Médicas; 2001. p. 75-85.

3 Agência Nacional de Vigilância Sanitária (Anvisa). Intervenções e medidas de prevenção e controle da resistência microbiana. Módulo V, 2005. [citado 2015 set. 12]. Disponível em URL: http://www.anvisa.gov.br/servicosaude/controle/ rede_rm/cursos/rm_controle/opas_web/modulo5/def_manuais2.htm.

4. Monjon P. Oral health and respiratory infection. J Can Dent Assoc 2002; 68(6):340-5.

5. Amaral SM, Cortes AQ, Pires FR. Pneumonia nosocomial: importância do microambiente oral. J Bras Pneumol 2009; 35(11):1116-24.

6. Patarroyo M, Gonçalves PF, Flecha OD. A doença periodontal como fator de risco para a pneumonia por aspiração - revisão de literatura. Periodontia 2008; 18(2):24-30.

7. Zanatta FB, Machado E, Zanatta GB, Fiorini T. Doença periodontal materna e nascimento prematuro e de baixo peso: uma revisão crítica das evidências atuais. ACM 2007; 36(1):96-102

8. Pineda LA, Saliba RG, El Solh AA. Effect of oral decontamination with chlorhexidine on the incidence of nosocomial pneumonia: a meta-analysis. Crit Care 2006; 10(1):R35.

9. Siempos II, Falagas M. Oral decontamination with chlorhexidine reduces the incidence of nosocomial pneumonia. Crit Care 2007; 11(1):402.

10. Gomes-Filho IS, Cruz SS, Rezende EJ, Dos Santos CA, Soledade KR, Magalhães MA. Exposure measurement in the association between periodontal disease and prematurity/low birth weight. J Clin Periodontol 2007; 34(11):957-63.

11. Scannapieco FA. A randomized trial of chlorhexidine gluconate on oral bacterial pathogens in mechanically ventilated patients. Crit Care 2009; 13(4):1-12.

12. Scannapieco FA, Ho AW. Potential associations between chronic respiratory disease and periodontal disease: analysis of national health and nutrition examination survey III. J Periodontol 2001; 72(1):50-6.

13. Almeida RF, Pinho MM, Lima C, Faria I, Santos P, Bordalo C. Associação entre doença periodontal e patologias sistêmicas. RPCG 2006; 22:379-90.

14. Pinheiro PG, Salani R, Aguiar ASW, Pereira LSP. Perfil periodontal de indivíduos adultos traqueostomizados com pneumonia nosocomial. R Periodontia 2007; 17(3):67-72.

15. Raghavendran K, Mylotte JM, Scannapieco FA. Nursing home-associated pneumonia, hospital-acquired pneumonia and ventilator-associated pneumonia: the contribution of dental biofilms and periodontal inflammation. Periodontol $20002007 ; 44: 164-77$. 
16. Sociedade Brasileira de Pneumologia e Tisiologia. Diretrizes brasileiras para tratamento das pneumonias adquiridas no hospital e das associadas à ventilação mecânica. J Bras Pneumol 2007; 33(Suppl 1):S1-S30.

17. Haringer DMC. Pneumonia associada à ventilação mecânica. Rev Pulmão 2009; Supl 2:S37-S45.

18. Pires JR, Matareli S, Ferreira RG, Toledo BEC, Zuza EP. Espécies de Candida e a condição bucal de pacientes internados em Unidade de Terapia Intensiva. Rev Assoc Paul Cir Dent $2011 ; 65(5): 332-7$.

19. Micek IST, Wunderink RG, Kollef MH, Chen C, Rello J, Chastre J. An international multicenter retrospective study of Pseudomonas aeruginosa nosocomial pneumonia: impact of multidrug resistance. Critical Care 2015; 19:219.

20. Senol G, Kirakli C, Halilçolar H. In vitro antibacterial activities of oral care products against ventilator-associated pneumonia pathogens. Am J Infect Control 2007; 35(8):531-5.

21. Toews GB. Nosocomial pneumonia. Am J Med Sci 1986; 291:355-67.

22. American Thoracic Society. Infectious Diseases Society of America. Guidelines for the management of adults with hospital-acquired, ventilator associated, and healthcare-associated pneumonia. Am J Resp Crit Care Med 2005; 171(4):388416.

23. Lisboa T, Faria M, Hoher A, Borges LAA, Gómez J, Schifelbain L, et al. Prevalência de infecção nosocomial em Unidades de Terapia Intensiva do Rio Grande do Sul. Rev Bras Terapia Intensiva 2007; 19(4):414-20.

24. Terpenning MS, Taylor GW, Lopatin DE, Kerr CK, Dominguez L, Loesche WJ. Aspiration pneumonia: dental and oral risk factors in an olderveteran population. J American Geriatric Society 2001; 49:557-63.

25. Vieira DRP, Feitosa DMZ, Alves MSC, Cruz MCFN, Lopes FF. Associação entre doença periodontal na gravidez e parto pré-termo baixo peso ao nascer. Odontol Clín-Cien 2010; 9(4):311-4.

26. Baelum V, Pisuithanakan S, Teanpaisan R, Pithpornchaiyakul W, Pongpaisal S, Papapanou PN, et al. Periodontal conditions among adults in Southern Thailand. J Periodontol Res 2003; 38:156-63.

27. Mayrand D. Virulence promotion by mixed bacterial infections. In: Jackson GG, Thomas H. The pathogenesis of bacterial infections. Berlin; 1985. p. 282-91.

28. Socransky SS, Smith C, Haffajee AD. Subgingival microbial profiles in refractory periodontal disease. J Clin Periodontol 2002; 29(3):260-8.

29. Roriz VM, Boaventura VL, Dalbello DNG. Perfil periodontal e episódios de pneumonias nosocomiais em pacientes internados em uma UTI: estudo piloto. ROBRAC 2014; 23:207-11.

30. Azarpazhooh AL, Leake JL. Systematic review of the association between respiratory diseases and oral health. J Periodontol 2006; 77(9):1465-82.

31. Sachdev M, Ready D, Brealey D, Ryu J, Bercades G, Nagle J, et al. Changes in dental plaque following hospitalisation in a critical care unit: an observational study. Crit Care 2013; 17(5):R18936.

32. Lindhe J, Rylander H. Experimental gingivitis in young dogs. Scand J Dent Res 1975; 83(6):314-26.

33. Shi Z, Xie H, Wang P, Zhang Q, Wu Y, Chen E, et al. Oral hygiene care for critically ill patients to prevent ventilator-associated pneumonia. Cochrane Database of Systematic Reviews 2013; 8:CD008367.

34. Chen W, Cao Q, Li S, Li H, Zhang W. Impact of daily bathing with chlorhexidine gluconate on ventilator associated pneu- monia in intensive care units: a meta-analysis. J Thorac Dis 2015; 7(4):746-53.

35. Bopp M, Darby M, Loftin KC, Broscious S. Effects of daily oral care with $0.12 \%$ chlorhexidine gluconate and a standard oral care protocol on the development of nosocomial pneumonia in intubated patients: a pilot study. J Dent Hyg 2006; 80(9):1-10.

36. Cruz F, Ziviani C. Possível relação entre a inadequada higiene oral e o aparecimento de infecções respiratórias em pacientes internados em UTI [Trabalho de Conclusão de Curso de Graduação]. Belém: Universidade Federal do Pará; 2006. p. 14-69.

Endereço para correspondência:

Rubem Beraldo dos Santos

Rua Dr. Liberato Salzano Vieira da Cunha, 807

Bairro Frota

96508-740 Cachoeira do Sul, RS

Telefone: (51) 3722-0446 / (51) 99714-0820

E-mail: rubemberaldorotary@gmail.com

Recebido: 06/04/2016. Aceito: 13/06/2016. 